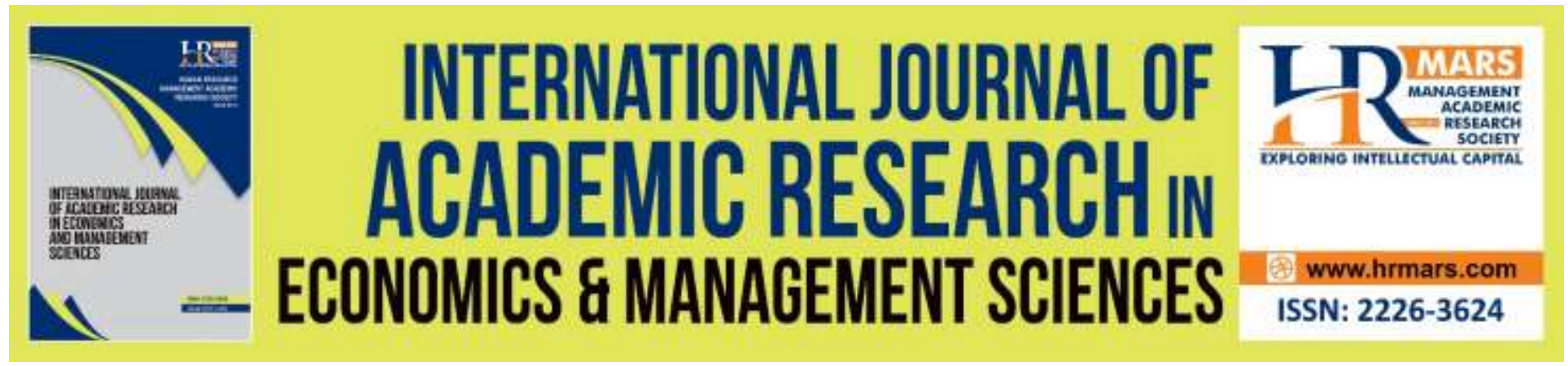

\title{
Investigating the Impact of Mental Abilities for Decision Makers on Crisis Management
}

Hasan Ali Al-Zu'bi, Talal Tayel ALabdallat, Emad Hamdi AL-Zou'bi

To Link this Article: http://dx.doi.org/10.6007/IJAREMS/v8-i3/6277

DOI: $10.6007 /$ IJAREMS/v8-i3/6277

Received: 13 July 2019, Revised: 01 August 2019, Accepted: 21 August 2019

Published Online: 17 September 2019

In-Text Citation: (Al-Zu'bi, ALabdallat, \& AL-Zou'bi, 2019)

To Cite this Article: Al-Zu'bi, H. A., ALabdallat, T. T., \& AL-Zou'bi, E. H. (2019). Investigating the Impact of Mental Abilities for Decision Makers on Crisis Management. International Journal of Academic Research in Economics and Managment and Sciences, 8(3), 1-11.

Copyright: (c) 2019 The Author(s)

Published by Human Resource Management Academic Research Society (www.hrmars.com)

This article is published under the Creative Commons Attribution (CC BY 4.0) license. Anyone may reproduce, distribute, translate and create derivative works of this article (for both commercial and non-commercial purposes), subject to full attribution to the original publication and authors. The full terms of this license may be seen at: $\underline{\text { http://creativecommons.org/licences/by/4.0/legalcode }}$

Vol. 8, No. 3, 2019, Pg. 1 - 11

http://hrmars.com/index.php/pages/detail/IJAREMS

JOURNAL HOMEPAGE

Full Terms \& Conditions of access and use can be found at http://hrmars.com/index.php/pages/detail/publication-ethics 


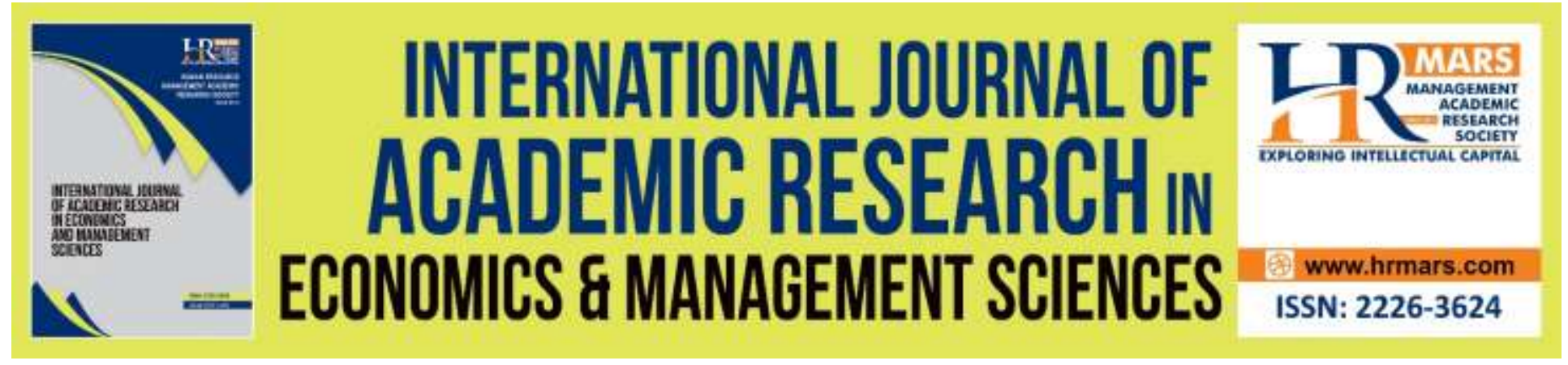

\title{
Investigating the Impact of Mental Abilities for Decision Makers on Crisis Management
}

\author{
Hasan Ali Al-Zu'bi (Ph.D) \\ Professor of Business Administration, Faculty of Business, Amman Arab University, Amman, Jordan \\ Email: hasanzubi63@gmail.com \\ Talal Tayel ALabdallat (Ph.D), Emad Hamdi AL-Zou'bi (Ph.D) \\ Business Administration \\ Email:t_abdallat@yahoo.com,dr.emadalzoubi@gmail.com
}

\begin{abstract}
The aim of the study was to test the impact of the mental abilities of decision makers on the effectiveness of crisis management in the banking industry of Jordan. The descriptive analytical approach was used to conduct this study. The study population represented the employees in the Bank of Jordan, while the sample of the study consisted of managers with experience in senior and middle management. A questionnaire was developed for the purpose of collecting the data, distributed to the sample of the study which reached (75) individuals. The statistical analysis was conducted on the data available from the questionnaire. The study concludes that, the most important ability is the self-management ability that significantly influence the effectiveness of crisis management. Accordingly, this study recommends the managers of the bank to understand the importance of and role of mental abilities in crisis management. Further, training and development of the employees to improve mental abilities may produce better results due to their positive role in decision-making.
\end{abstract}

Keyword: Mental Abilities, Decision Makers, Effectiveness, and Crisis Management.

\section{Introduction}

As the 21st century enters, business organizations generally operate in a climate of environmental uncertainty and uncertainty, which makes the probability of crises very high. To address these crises and mitigate their negative effects, organizations seek to adopt concepts and applications that help them overcome these risks in order to maintain their survival and growth.

The mental abilities of the decision-making community are one of the most important concepts of behavior and strategy for its importance in helping organizations to excel and innovate within the competitive environment in which they work, thus ensuring their survival and continuity in work. The importance of mental abilities has increased in recent years due to the rapidly changing 
dynamic environment, which required the organizations to build and develop some skills, especially in the higher administrative levels, as the entity responsible for determining the future direction of the organization and managing and investing all resources available.

No organization can succeed in managing the crises that occur in the work environment due to different reasons, except with members of the higher administrative levels who have distinct mental abilities and are able to deal with these crises with an open mindset that enables them to mitigate the negative effects of the crisis and benefit as much as possible from the positives of these crises.

This study tries to fill in the lack of studies that examined crisis management particularly in banks where the importance of this phenomenon is significant due to the nature of business. Through a review of previous studies, no study has been found dealing with mental abilities with the effectiveness of crisis management, especially in the Jordanian banking industry. As for the significance of this study is determined by helping the senior management banks in Jordan to improves the effectiveness of crisis management by developing a conceptual model of mental abilities for decision makers as appropriate approach for improvement.

Hence, this study is motivated to find out the most important dimensions of mental abilities of decision makers particularly in banking industry of Jordan. Further, to identify the level of effectiveness of crisis management iis also the point of interest. Try to make some recommendations to enhance the importance of the role of mental abilities in crisis management.

\section{Theoretical Framework}

\section{Mental Abilities of Decision-Makers}

Determining the precise concept of the mental abilities of decision-makers is of some difficulty, because most researchers and interested people focus on a concept of abilities in general. But what interest us in this research are the mental abilities that interested in the study of researchers in the field of strategic management, which includes the impact of all parts of the organization.

Robbins (2003) defined it as an ability to influence the group to achieve goals. Huczynski and Buchanan (2001) have defined them as the abilities to ensure the impact on the individual or group of individuals in order to direct their efforts towards dealing with the goals and work to achieve them. Lussier \& Achua (2007) both have been confirmed that the mental abilities of decision-makers constitute the absolute source of the information adopted by the organization in dealing with the problems it faces in work. In other words, it is the incubator for all administrative levels responsible for the current and future performance of the organization through its role in rationalizing decision-making processes within the organization (Schermerhorn, 2008).

The mental abilities of decision-makers play an important role in organizations and for relatively long periods of time, thus contributing to the achievement of wide changes in the organization through its influence in the process of strategic thinking. It also plays a vital role in the formulation of long-term plans through the development of the vision and mission of the organization, which requires courage, patience, sacrifice, loyalty, sincerity, honesty and discipline of the organization's strategic leaders. 
The importance of the mental abilities of decision-makers is reflected in the results that contribute to the achievement of the organizations, the most important of which is dealing with human resources in a fair and respectful manner that contributes to enhancing their morale and ensuring that human resources are provided with all information to improve their performance levels (Dane \& Pratt, 2007).

\section{Dimensions of Mental Abilities}

Intuition Abilities: There is a difference in the views of researchers on the definition of intuition, it includes guessing, expectation and perception, that is, judgment on things without thinking, but on what one sees in the subconscious mind, And thus is a sophisticated thinking does not connect only the creative glow of the mind suddenly and strongly to provide them with inspiration (Dane \& Pratt, 2007). Others also point out that intuition stems from a sense of not thinking, the truth is that intuition is not related to emotion but to skills and ways of thinking (Nyatanga \& Vocht, 2008).

Visualization Abilities: The visualization of the integrated unit reflects a set of subjective and objective factors that lead to new results of value to the individual (Sharif, 2002). It includes looking at things and phenomena and problems a new perspective and relationships is unfamiliar, and the individual research and survey and linking things to make new things (Al-Rawi, 2005). In other words, it helps to find new ways of thinking and learning that fundamentally change the processes and outputs of the organization.

Imagination Abilities: These abilities reflect the potential of decision makers to predict change and the impact of new events and expanding the scope of vision, adopting risks and building confidence (Chuang, 2013). It also includes the ability to understand the nature of the organization as an integrated system, and must deal with it so as to understand its objectives, regulations and plans, and the ability to organize work and distribute duties and powers among all organizational levels (Murch, 2001).

Self - Management Abilities: It includes the ethical integration of self-orientation and the balance of work and life requirements. That is, it reflects the individual's perception of self as a natural, social and spiritual existence, In addition to its ability to adapt positively to changes in the workers' environment. It is also linked to the ability to base the rules of ethics, integrity, work balance, personal leadership, flexibility and self-awareness of development (Al-Kubaisi \& Hatem, 2018).

\section{Effectiveness of Crisis Management}

The concept of crisis is one of the most widespread concepts in the modern world, affecting the various aspects of life. No one disputes that crises are a major part of the reality of human life. This leads to serious thinking about how to deal with them effectively and effectively to reduce their negative results, and to benefit if possible from their positive results (Wahab, 2015).

The crisis is defined as a transitional condition characterized by imbalance and represents a turning point in light of which future events lead to a major change (Random, 1969). Phelps (1986) defines the crisis as an emergency or a sudden event that disrupts the organization, which 
weakens its competitive position and requires quick action and immediate attention, so that any event can be classified as a crisis depending on the degree of disruption of the event in the normal course of the organization.

Crisis management attempts and systematic efforts are ongoing to determine their direction and create the appropriate climate in the face of the crisis.

The effectiveness of crisis management is a mixture of know-how, understanding, skills, experience, time, cost, training, rehabilitation and awareness. The effectiveness of crisis management is defined as crisis management capacity to avoid potential crises or stakeholders' belief that short-term and long-term success in crisis management is greater than failure. The effectiveness of crisis management should also be measured by the level of mitigating the impact of crises on organizational objectives (Salman \& Mahawi, 2016).

\section{Dimensions of the Effectiveness of Crisis Management}

Speed Response Decision: When the crisis occurs in the organization, the first response is often confusion and fear, and we may remain moments wondering, "What do we do now?" Crisis management decisions are a specific set of decisions to deal with crises in order to stop their repercussions and follow up their developments and find the best means to deal with them and face any exceptional or emergency circumstances. Crisis management requires a set of administrative decisions in a short and specific time. In uncertain circumstances, there is not enough time to analyze and study the situation, and the confrontation must be quick and precise so as not to aggravate the crisis.

Communications and Information Flow: The main principle of communication in crises is not to be isolated in the event of a crisis or a problem. Communication is the most effective in crisis conditions. Crisis communication is the transfer and exchange of ideas, information, crisis instructions, team members and supporting bodies using formal and informal channels of communication in order to deliver the right quantity and type of information in a timely manner to the decision-maker in order to overcome the crisis.

Crowd and Mobilization of Resources: Crisis management is the best use of time and resources (Ezzeldin, 2014). Crowd and mobilization of resources is the key to the crisis. The mobilization must be planned as a systematic and ongoing process designed to regulate the effective use of available resources to deal effectively with and respond to potential crises at all stages while preparing for situations that appear disproportionately in the face of these crises and mitigate their effects (Salman \& Mahawi, 2016).

\section{Conceptual Model}

Figure (1) shows study model, which shows the nature of the effect of the dimensions of the independent variable (Mental Abilities of Decision Makers) on the dimensions of the dependent variable (Effectiveness of Crisis Management). 


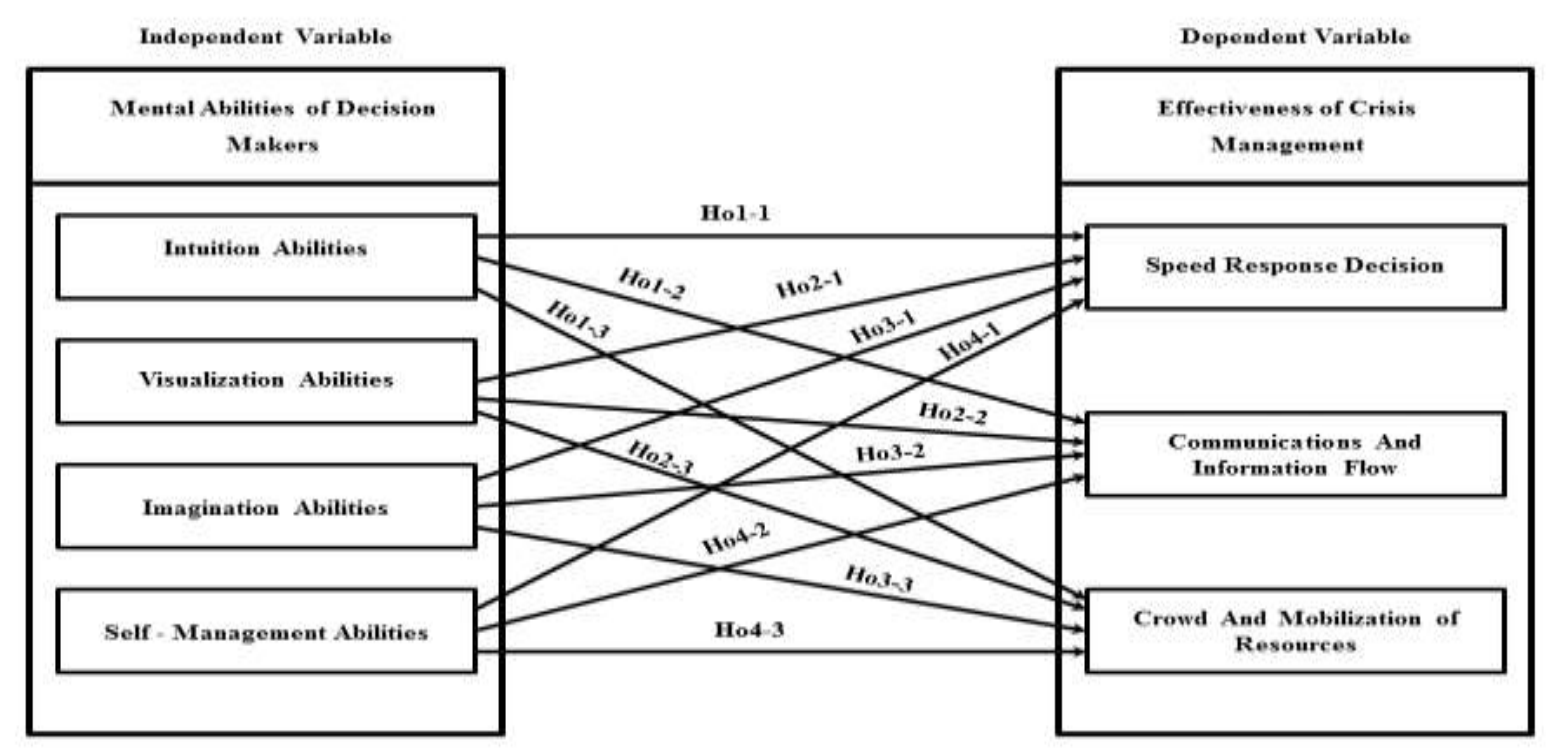

Figure 1; Study Model

\section{Study Hypotheses}

Based on the study problem and objectives, the study seeks to test the following hypotheses: $\mathrm{H} 1$ : The intuition abilities positively impact in speed response decision.

$\mathrm{H} 2$ : The intuition abilities have a positive relationship communications and information flow.

$\mathrm{H} 3$ : The intuition abilities positively impact crowd and mobilization of resources.

$\mathrm{H} 4$ : The visualization abilities have a positively association with speed response decision.

$\mathrm{H} 4$ : The visualization abilities positively impact the communications and information flow.

H5: The visualization abilities positively impact the crowd and mobilization of resources.

H6: The imagination abilities positively impact the speed response decision.

$\mathrm{H7}$ : The imagination abilities positively impact the communications and information flow.

H8: The imagination abilities positively impact the crowd and mobilization of resources.

H9: The self - management abilities positively impact the speed response decision.

$\mathrm{H} 10$ : The self - management abilities positively impact the communications and information flow.

H11: The self - management abilities positively impact the crowd and mobilization of resources.

\section{Methodology of the Study}

\section{Population and Sample}

The study is focused on banking industry due to the developmental role of Banks in Jordanian economy. The sample of the respondents was chosen from the Managers in senior management and middle management, according to the criterion of experience in the field of management. Total number of respondents selected for this study is 75 on convenience-based sampling method. After retrieving the questionnaires, three (3) questionnaires were excluded for the analysis due to incomplete response. The number of valid questionnaires is 72 . 
The dimensions of the independent variable (Mental Abilities of Decision Makers) were measured through questionnaire adopted from Chuang (2013) and Al-Kubaisi \& Hatem (2018). To measure the dependent variable (Effectiveness of Crisis Management), the following studies were based Salman \& Mahawi (2016) and Ezzeldin (2014).

\section{Instrument Validity and Reliability}

To verify the validity and stability of instrument several tests has been conducted. To test the validity of the construct the questionnaire was presented to a group of experts and specialists who have experience in this area to verify the validity. Further, to measure the internal consistency between the questions of the questionnaire Cronbach's Alpha coefficient was measured. Results indicated that the Cronbach's Alpha coefficient for all the items of the construct was greater than (0.70), It ranged from (0.81-0.88) and this indicates the existence of internal consistency between the items of the scale.

\section{Results and Discussion}

After running the analysis, The RMSEA value was (0.048), which indicated goodness of fit for the model. Also, CMIN/DF indicated a model fitness with a value of (3.423). GFI value is (0.979) and within acceptable range. In addition, NFI value is (0.971) and CFI value is (984) which shows that both values are within the acceptable ranges. The Model Fitness indices of Structural Equation Model is shown in Table 1.

Table 1: Fitness Indices of Structural Model

\begin{tabular}{ll}
\hline X2 & 13.693 \\
X2 /df & 3.423 \\
Normed fit index (NFI) & 0.971 \\
Comparative fit index (CFI) & 0.984 \\
Goodness of fit index (GFI) & 0.979 \\
root mean square error of approximation(RMSEA) & 0.048 \\
\hline
\end{tabular}


INTERNATIONAL JOURNAL OF ACADEMIC RESEARCH ECONOMICS AND MANAGEMENT SCIENCES Vol. 8, No. 3, 2019, E-ISSN: 2226-3624 ㄷ 2019 HRMARS
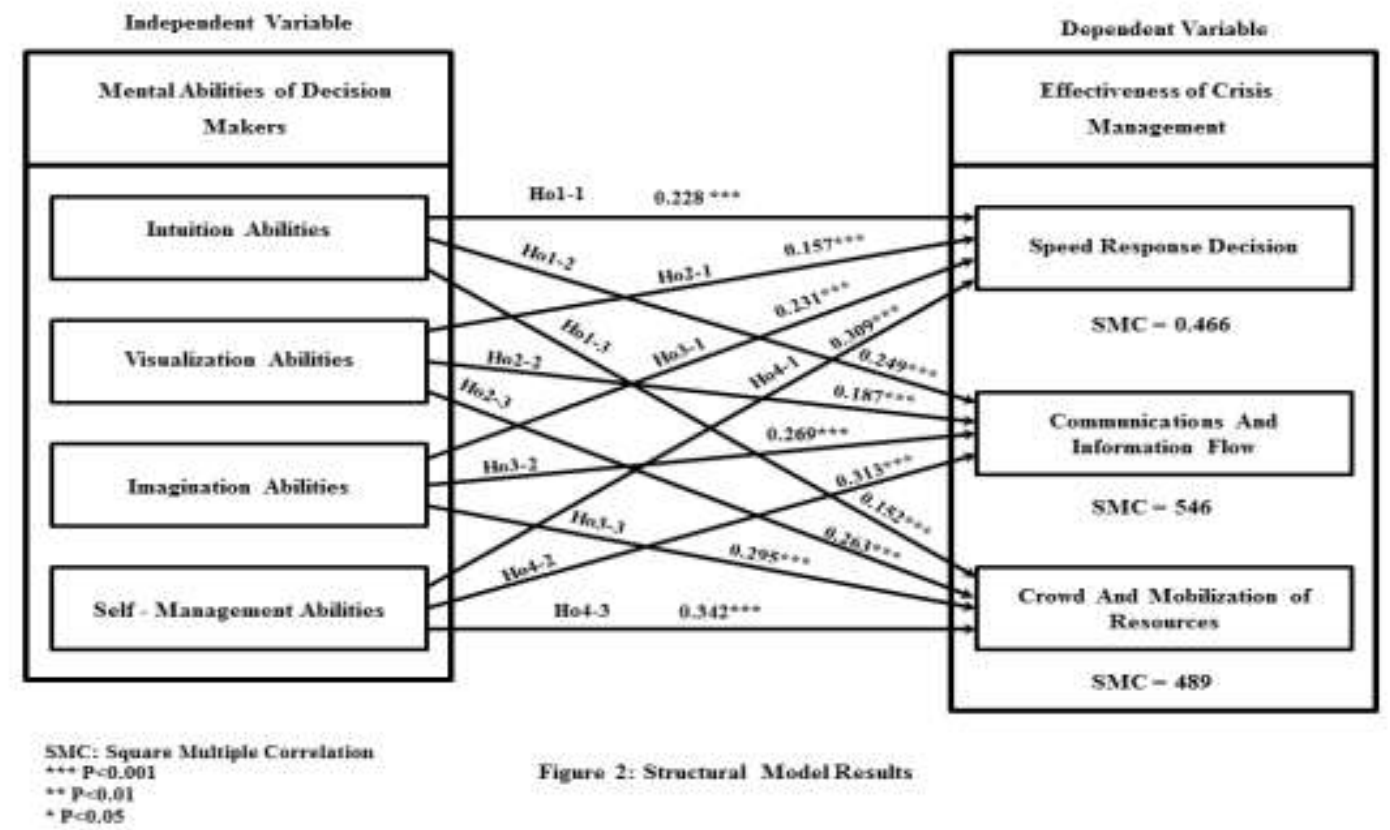

Figure 2: Structural Model Results

Table 2: SEM Result

\begin{tabular}{|c|c|c|c|c|c|c|c|}
\hline \multirow[b]{2}{*}{ Hypothesis } & \multicolumn{2}{|c|}{ Regression Weights } & \multirow[b]{2}{*}{ Estimate } & \multirow[b]{2}{*}{ S.E. } & \multirow[b]{2}{*}{ C.R. } & \multirow[b]{2}{*}{ P value } & \multirow[b]{2}{*}{ Results } \\
\hline & From & To & & & & & \\
\hline $\mathrm{H} 1$ & Intuition Abilities & Speed Response Decision & 0.228 & 0.031 & 7.406 & $* * *$ & Rejected \\
\hline $\mathrm{H} 2$ & Intuition Abilities & Communications and Information Flow & 0.249 & 0.029 & 8.699 & $* * *$ & Rejected \\
\hline $\mathrm{H} 3$ & Intuition Abilities & Crowd and Mobilization of Resources & 0.152 & 0.031 & 4.926 & $* * *$ & Rejected \\
\hline $\mathrm{H} 4$ & Visualization Abilities & Speed Response Decision & 0.157 & 0.030 & 5.284 & $* * *$ & Rejected \\
\hline H5 & Visualization Abilities & Communications and Information Flow & 0.187 & 0.036 & 5.197 & $* * *$ & Rejected \\
\hline $\mathrm{H} 6$ & Visualization Abilities & Crowd and Mobilization of Resources & 0.263 & 0.033 & 7.956 & $* * *$ & Rejected \\
\hline $\mathrm{H} 7$ & Imagination Abilities & Speed Response Decision & 0.231 & 0.057 & 4.025 & $* * *$ & Rejected \\
\hline $\mathrm{H} 8$ & Imagination Abilities & Communications and Information Flow & 0.269 & 0.041 & 6.493 & $* * *$ & Rejected \\
\hline $\mathrm{H} 9$ & Imagination Abilities & Crowd and Mobilization of Resources & 0.295 & 0.035 & 6.435 & $* * *$ & Rejected \\
\hline $\mathrm{H} 10$ & $\begin{array}{l}\text { Self-Management } \\
\text { Abilities }\end{array}$ & Speed Response Decision & 0.309 & 0.054 & 5.036 & $* * *$ & Rejected \\
\hline $\mathrm{H} 11$ & $\begin{array}{l}\text { Self - Management } \\
\text { Abilities }\end{array}$ & Communications and Information Flow & 0.313 & 0.031 & 5.274 & $* * *$ & Rejected \\
\hline $\mathrm{H} 12$ & $\begin{array}{l}\text { Self - Management } \\
\text { Abilities }\end{array}$ & Crowd and Mobilization of Resources & 0.342 & 0.034 & 6.389 & $* * *$ & Rejected \\
\hline
\end{tabular}

From Figure (2) and Table (2), it shows that the hypothesis test, in determining the significance of each path coefficient, estimate of regression weight, standard error of regression weight, and the critical ratio of regression weight, $(C . R=$ dividing the regression weight estimated by the estimate of its standard error gives) were used.

Table (2) presents each parameter's C.R., Estimate and S.E. Hence, intuition abilities has a significant positive and direct impact on speed response decision, communications and information flow, and crowd and mobilization of resources $(\beta=0.228,0.249$, and 0.152$),(C . R=$ 7.406, 8.699, and 4.926), (P-value $=* * *, * * *$, and $* * *)$ or $\mathrm{H} 1, \mathrm{H} 2$, and $\mathrm{H} 3$, is supported. 
In the same analysis, visualization abilities has a significant positive and direct impact on speed response decision, communications and information flow, and crowd and mobilization of resources $(\beta=0.157,0.187$, and 0.263), (C.R=5.284, 5.197, and 7.956), ( $\mathrm{P}$-value $=* * *, * * *$, and $* * *$ ) or $\mathrm{H} 4, \mathrm{H} 5$, and $\mathrm{H} 6$, is supported.

As for the third dimension of Imagination Abilities, the results of the analysis were a significant positive and direct impact on speed response decision, communications and information flow, and crowd and mobilization of resources $(\beta=0.231,0.269$, and 0.295$),(C . R=4.025,6.493$, and 6.435), ( $\mathrm{P}$-value $=* * *, * * *$, and $* * *)$ or $\mathrm{H} 7, \mathrm{H} 8$, and $\mathrm{H} 9$, is supported.

Finally, Challenge has a significant positive and direct impact on speed response decision, communications and information flow, and crowd and mobilization of resources $(\beta=0.309$, 0.313, and 0.342), (C.R=5.036, 5.274, and 6.389), (P-value $=* * *, * * *, * * *$, and $* * *)$ or $\mathrm{H} 10, \mathrm{H} 11$, and $\mathrm{H} 12$ is supported.

The result of this study is in line with previous studies of Al-Kubaisi \& Hatem (2018) and Salman \& Mahawi, (2016). The aim of study was to examine the effect of mental abilities of decisionmakers in defining the strategic orientation. Their findings indicate that dimensions of mental abilities of decision-makers have a positive effect on defining the strategic orientation. Salman \& Mahawi, (2016) investigated the role of practices by the Managing of human resources on effectiveness of organizational crisis Management. They found out that there was direct effect of practices of Managing of human resources on effectiveness of organizational crisis Management dimensions.

\section{Conclusions and Recommendations}

Based on the findings of the study, some conclusions were reached. The most important of these was that the ability of self - management abilities as one of the dimensions of mental abilities had the greatest impact on the effectiveness of crisis management. Where the impact on the speed of the response resolution reached $(\beta=0.309)$, this means that a change of one unit in the self - management abilities will change the speed response decision by (\%30.9). The impact on the communications and information flow was $(\beta=0.313)$ the change in self - management abilities by one unit would impact the value of (\%31.3) in the communications and information flow. While its greatest impact was crowd and mobilization of resources, with a beta value of (0.342) which means that the impact of crowd and mobilization of resources was (\%34.2).

In addition, it is concluded that mental abilities have a positive impact on the effectiveness of crisis management. This demonstrates the awareness for decision-makers for the importance of mental abilities in crisis management.

The study recommends that the decision makers of the banks should enhance and develop the mental abilities of the role played by decision makers, especially in the management of crises, which is reflected positively in reducing the negative impact on the performance of banks. The study also recommends that researchers may conduct future studies related to studying other dimension of decision making and linking them with mental abilities. Further, there is a need to verify the results of this study in other sectors and socio-economic settings.

\section{References}

Wahab, A. H. (2015). Effective crisis management portal to achieve competitive advantage, Journal of ljtihad for Legal and Economic Studies, (8), Jun, 274-299. 
Chuang, Szu-Fang (2013). Essential Skills for Leadership Effectiveness in Diverse Workplace Development, Journal for Workforce Education and Development, 6 (1), spring, 1-23.

Dane, E., \& Pratt, M. (2007). Exploring Intuition and Its Role in Managerial Decision Making, Academy of Management Review, 32 (1), 33-54.

Ezzeldin, A. G. (2014). Decision Support System in the Crisis Management Unit, International Journal of Humanities and Social Science, 4, 8(1), 169-173.

Huczynski, A., \& Buchanan, D. (2001). Organizational Behavior: an Introductory Text, 4th Edition, Harlow, New York, Prentice - Hall.

Jamil, A. (2010). The Variety of Cognitive Patterns and Strategic Leadership Patterns Specified for the Effectiveness of The Senior Management Team, unpublished doctoral dissertation, Baghdad University.

Al-Kubaisi, Salah \& Hatem, A. (2018). Reflecting the mental abilities of decision-makers in defining the strategic orientation, Journal of Economic and Administrative Sciences, 24 (105), 25-48.

Lussier, Robert, N., \& Achua, Christopher, F. (2007). Effective leadership, $3^{\text {rd }}$ ed, New York, Irwin. Murch, R. (2001). Project Management: Best Practices for IT Professionals, USA, Prentice Hall, Inc. Nyatanga, B. \& Vocht, H. D. (2008). Intuition in clinical decision-making: a psychological penumbra, International Journal of Palliative Nursing, 14(10), 492-496.

Random. H. (1969) .Random House Dictionary of English Language, New York, Random House, P.491.

Al-Rawi, S. (2005). Factors of the Internal Environment and the Environment of the Task and Its Impact on Technical Innovation, Master Thesis unpublished, University of Mosul.

Robbins, S. P. (2003). Organizational behavior. $10^{\text {th }}$ Edition. San Diego: Prentice Hall.

Phelps, N. (1986). Setting up A Crisis Recovery Plan, Journal of Business Strategy, 6 (4).

Salman, F. \& Mahawi, R. (2016). The role of practices by the Managing of human resources on effectiveness of organizational crisis Management, Journal of Economic and Administrative Sciences, 22 (94), 183-203.

Schermerhorn., John, R. (2008). Management. $9^{\text {th }}$ ed. Hoboken, NJ: John Wiley.

Sharif, J. (2002). The Impact of the Empowerment Strategy in Enhancing Organizational Creativity, PhD Dissertation, University of Mosul. 